\title{
University of Sussex
}

Economics

\section{Working Paper Series}

\author{
No. 64-2013 \\ Bootstraps for Meta-Analysis with an Application to the Impact \\ of Climate Change \\ Richard S.J. Tol \\ Department of Economics, University of Sussex \\ Institute for Environmental Studies and Department of Spatial \\ Economics, Vrije Universiteit, Amsterdam, The Netherlands \\ Tinbergen Institute, Amsterdam, The Netherlands \\ R.Tol@sussex.ac.uk
}

Abstract: Bootstrap and smoothed bootstrap methods are used to estimate the uncertainty about the total impact of climate change, and to assess the performance of commonly used impact functions. Kernel regression is extended to include restrictions on the functional form. Impact functions do not describe the primary estimates of the economic impacts very well, and monotonic functions do particularly badly. The impacts of climate change do not significantly deviate from zero until 2.5$3.5^{\circ} \mathrm{C}$ warming. The uncertainty is large, and so is the risk premium. The ambiguity premium is small, however. The certainty equivalent impact is a negative $1.5 \%$ of income for $2.5^{\circ} \mathrm{C}$, rising to $15 \%(50 \%)$ for $5.0^{\circ} \mathrm{C}$ for a rate of risk aversion of 1 (2).

JEL classification: C14, Q54

Key words: impacts of climate change, kernel regression, bootstrap, risk aversion, ambiguity aversion 


\section{Introduction}

Uncertainty is a key concern about climate change. Whereas the uncertainties about future emissions (Webster et al. 2003), the response of the climate system (Annan and Hargreaves 2011) and the implications for policy (Weitzman 2009) have been widely discussed, the uncertainties about the impact of climate change have received less systematic attention. This

paper helps fill that gap. It explores the use of bootstrap and kernel methods for meta-analysis with few observations; and the use of meta-analysis for estimating the uncertainty about a relationship. It applies these methods to the impact of climate change.

(Tol 2012a) also explores the uncertainty about the total economic impact of climate change, using the smoothed bootstrap. That paper uses a single functional form for extrapolation. The current paper compares the smoothed bootstrap to the bootstrap and to kernel regression. Kernel regression analysis is extended to restrictions on the functional form. All procedures are readily replicable and can be applied to other data sets. In contrast to the previous paper, the current one tests alternative functional forms, so that we can include both risk and ambiguity aversion in the assessment (Lange and Treich 2008; Millner et al. 2013).

The paper is organized as follows. Section 2 presents the data on the impacts of climate change, and Section 3 the impact functions used in previous studies. Section 4 discusses the statistical methods. Section 5 reviews the results for the impacts of climate change, and Section 6 for its certainty and ambiguity equivalents. Section 7 concludes.

\section{Data}

There are 17 studies and 20 estimates of the global welfare impacts of climate change. These studies used different methods. (Nordhaus 1994a) interviewed a small number of presumed experts. (Fankhauser 1994;Fankhauser 1995;Nordhaus 1994b;Nordhaus 2008;Tol 1995;Tol 2002a;Tol 2002b) multiplied estimates of the "physical effects" of climate change with estimates of their price, and added up the result. (Bosello et al. 2012;Roson and van der Mensbrugghe 2012) also use estimates of the physical impacts but as input into computing the general equilibrium effects on welfare. (Maddison 2003; Mendelsohn et al. 2000b; Mendelsohn et al. 2000a;Nordhaus 2006) use observed variations (across space) in prices and expenditures to discern the effect of climate. (Maddison and Rehdanz 2011;Rehdanz and Maddison 2005) use the relationship between self-reported well-being and climate.

There is broad agreement between these studies in four areas (Tol 2009). First, the welfare effect of a doubling of the atmospheric concentration of greenhouse gas emissions on the current economy is relatively small-equivalent to losing a few percent of income. The impact of a century of climate change is roughly equivalent to a year's growth in the global economy.

Second, the initial benefits of a modest increase in temperature are probably positive, followed by losses as temperatures increase further. Figure 1 illustrates this pattern. The 
initial benefits arise partly from $\mathrm{CO}_{2}$ fertilization, and partly from reduced heating costs and cold-related health problems in temperate zones. However, the initial warming can no longer be avoided; these are sunk benefits, and do not affect decisions about emission reduction.

Third, as illustrated in Figure 1, the uncertainty is vast and right-skewed. Undesirable surprises are more likely than desirable surprises of equal magnitude. For instance, the climate sensitivity - the equilibrium warming due to a doubling of the atmospheric concentration of carbon dioxide - is bounded from below by the laws of physics but it is hard to put an upper bound on its value. It is relatively easy to paint disastrous pictures of the impacts of climate change - rapid sea level rise in the Bay of Bengal leading to mass migration and nuclear war - but difficult to imagine that climate change would make the world prosperous and peaceful. Most estimates are for $3^{\circ} \mathrm{C}$ of global warming or less, but climate change may well go beyond that. The uncertainties about the impacts are compounded by extrapolation (Tol 2012b).

Fourth, not shown in Figure 1, poorer countries tend to be more vulnerable to climate change. Poorer countries have a large share of their economic activity in sectors, such as agriculture, that are directly exposed to the weather. Poorer countries tend to be in hotter places, and thus closer to their biophysical limits and with fewer technical and behavioral analogues. Poorer countries also tend to be worse at adaptation, lacking resources and capacity (Yohe and Tol 2002).

Having reviewed comparative static estimates of the total economic impact of climate change, the next section discusses impact functions.

\section{Impact functions}

Different analyses of the welfare impacts of climate change assume different functions that relate impact $I$ to the global mean temperature $T$. Numerical analyses often use a variant of

$$
I=I(T)=\alpha_{1} T+\alpha_{2} T^{2}+\alpha_{6} T^{6}
$$

(Tol 2009) suggests $\alpha_{6}=0$. (Nordhaus 1992; Nordhaus 2008) has $\alpha_{1}=\alpha_{6}=0$. And (Weitzman 2012) has $\alpha_{1}=0$. I refer to these functions by the names of their main proponents. (Hope 2008) uses the function

$$
I=I(T)=\kappa T^{1.3}
$$

Note that Hope and Nordhaus add another component to their impact function, describing "catastrophic impacts" of severe warming. As these are largely omitted from the impact estimates of Section 2, there is no basis for calibration and catastrophic impacts are therefore omitted.

Analytical studies (Karp 2003;van der Ploeg and Withagen 2012) typically abstract from the complications of computing temperature, and often use

$$
I=I(C)=\beta C^{2}-\beta_{0}
$$


where $C$ is the atmospheric concentration of carbon dioxide emissions. Ignoring carbon cycle dynamics, concentrations are proportional to cumulative emissions. Ignoring climate dynamics, temperature is proportional to the natural logarithm of the concentration of carbon dioxide: $T=\gamma \ln \left(C / C_{0}\right)$. Thus, (3) can be rewritten as

$$
I=I(T)=\beta C_{0}^{2}\left[\exp \left(\frac{2}{\gamma} T\right)-1\right]
$$

with $\gamma=4.33$ (assuming a $3^{\circ} \mathrm{C}$ warming for a doubling of carbon dioxide).

Having reviewed impact estimates and impact functions from previous literature, the next section discusses the methods used in the current paper.

\section{Methods}

The five alternative impact functions of Section 3 are fitted, using OLS, to the data of Section 2. In order to assess the uncertainty about the models, particularly when extrapolating to $5^{\circ} \mathrm{C}$ warming, I use the standard bootstrap (Efron and Tibshirani 1994). That is, I draw, with replacement, 20 pseudo-observations from the 20 data points and re-estimate the five models using OLS. I do so 10,000 times.

As an alternative to the parametric models of Section 3, I use kernel regression. I use a bivariate normal kernel; and use the (Silverman 1986) rule-of-thumb to set the bandwidth equal to $h=1.06 \Sigma^{-0.5} n^{-0.2}$, where $\Sigma$ is the sample covariance matrix and $n=20$ is the sample size.

Standard kernel regression (Takezawa 2006) does not impose any functional form on $I(T)$. Indeed, that is one of its main strengths. However, by construction, zero climate change has zero impact: $I(T=0)=0$. I therefore constrain the kernel regression to go through the origin by adding a $21^{\text {st }}$ observation with $h^{*}=h / 10$. The division by ten is ad hoc, chosen by experimentation; see the appendix. If the bandwidth of the restriction is too large, it is not met in expectation; if the bandwidth is too small, the restriction holds only locally and the kernel function loses its smoothness.

The standard bootstrap assumes that the observed values are the only ones that could have been observed. This is a tall assumption in any case, and it matters in small samples. I therefore use the smoothed bootstrap (Tibshirani 1988) to reassess the uncertainty about the models. That is, I draw 20 pseudo-observations from the bivariate kernel distribution and reestimate the models using OLS. I do so 10,000 times.

Having discussed the methods to combine impact estimates and impact functions, the next section discusses the results.

\section{Results}


Figure 1 shows the 20 estimates of Table 1, as well as the six fitted models. The kernel regression is closest to the data. It suggests a quadrilinear function, going from 0 to $1.5 \%$ of GDP for a $0.3^{\circ} \mathrm{C}$ warming, falling to $-5.9 \%$ for a $3.9^{\circ} \mathrm{C}$ warming, before being bumped up to match the estimate by (Roson and van der Mensbrugghe 2012). The kernel estimator treats the estimate by (Maddison and Rehdanz 2011) as an outlier: The confidence interval widens, but the expectation is far from the data point. Remarkably, the impacts of climate change only become significant at $4^{\circ} \mathrm{C}$.

The models by Tol and Nordhaus are hard to distinguish. The model by van der Ploeg is close but more curved, while the Hope model is more optimistic. The model by Weitzman is similar but bends back for large warming.

Table 2 has the model fit. The metric is the re-scaled likelihood. For each fitted model, the log-likelihood is computed, exponentiated, and rescaled so that the likelihood of the five models adds up to unity. The Weitzman model has the best fit: Its relative likelihood is $28 \%$. Nordhaus and Tol model follow with $21 \%$, and Hope and van der Ploeg with $15 \%$. The data does not really discriminate between the functional forms. In fact, none of the models describe the data really well.

Figure 2 shows the bootstrap result. 10,000 artificial data sets were created and the models reestimated and extrapolated to $5^{\circ} \mathrm{C}$ warming. Figure 2 shows the mean and the $90 \%$ confidence interval. The models by Nordhaus and van der Ploeg are hard to distinguish, both in mean and confidence interval. The Hope model is similar too, albeit less pessimistic. For all three models, the confidence interval roughly symmetric: The distance between the mean and the upper bound is about the same as the distance between the lower bound and the mean. The model by Tol follows the same pattern as in Figure 1. The initial benefits are more pronounced, but not significant. The later damages do differ significantly from zero. The confidence interval is left-skewed: The lower bound is further from the mean than the upper bound. The mean of the Weitzman model behaves not at all like its mode: It accelerates towards large and negative impacts. The confidence interval is left-skewed, even if the upper bound only has moderately negative impacts.

Table 2 has the model fit, in this case the mean and $90 \%$ confidence interval of the relative likelihood. The Weitzman model performs best at 44\%. The gap with the Tol model, at 22\%, is much larger. Other three models perform worse than in the best guess. The confidence intervals about these probabilities are very wide, particularly for the Weitzman and Tol models. There are samples in which these are the only models with a reasonable fit, and samples in which these models fit very badly. The other three models never do quite well.

Figure 3 shows the bivariate kernel density that forms the basis of the kernel regression (Figures 1 and 2) and the smoothed bootstrap. There are five modes. The global mode is at a warming of $2.5^{\circ} \mathrm{C}$ warming (for which we have the most observations) and an impact of $1.1 \%$. There are local modes around $1{ }^{\circ} \mathrm{C}, 3^{\circ} \mathrm{C}$ and $5^{\circ} \mathrm{C}$ of warming that follow from the observations, and one at $0^{\circ} \mathrm{C}$ due to the restriction imposed. Figure 1 shows the expectation 
of the impact conditional on the temperature. Figure 2 repeats that information, and adds the $90 \%$ confidence interval. See discussion above.

Figure 2 shows the results for the five models fitted to realizations of the smoothed bootstrap. These are no substantial differences between the bootstrap and the smoothed bootstrap for the Nordhaus and van der Ploeg models. For the other three models, however, the smoothed bootstrap is less pessimistic, although the difference is never significant. The Hope and Tol models are qualitatively similar for bootstrap and smoothed bootstrap. The smoothed bootstrap is less pessimistic for the Weitzman model too. The upper bound of the Weitzman model, however, turns decidedly positive. As a result, the Weitzman results are insignificant beyond $4^{\circ} \mathrm{C}$ (albeit very large).

Table 2 shows that the model fit changes too. Weitzman still fits best, at a mean of $31 \%$, followed by Tol at 26\%, Nordhaus at $16 \%$ and van der Ploeg and Hope at $14 \%$ each. The confidence intervals are narrower but still very wide.

Figure 4 shows the Bayesian model average for the bootstrap and the smoothed bootstrap, using the average probabilities in Table 2 as model weights. The result is largely a compromise between the Tol and Weitzman models. Compared to the Weitzman model, impacts are more positive at first and not as negative (but significantly so) later.

Having discussed the total economic impact of climate change, the next section turns to welfare equivalents.

\section{Risk and ambiguity premiums}

The top panel of Figure 4 shows the expected impacts, according to the smoothed bootstrap, of the five alternative models, and their weighted average. Results for the bootstrap are qualitative similar. The average is close to the Tol model.

The bottom panel of Figure 4 shows the certainty equivalent impacts. Instead of averaging monetized impacts, welfare impacts were averaged and then monetized. Figure 4 shows the results for a risk aversion of one and an income of \$5700/person/year, the global average in 2005. Graphically, risk premiums - the differences between the certainty equivalent and the expected impacts - are small for all models except Weitzman's. Table 3 confirms this, and shows that it holds for a risk aversion of two and for the bootstrapped impacts as well.

Small risk premiums should come as no surprise: Projected impacts are small relative to income. Global average income is well above subsistence level. The Weitzman model is the exception, with a substantial probability that impacts make a real dent in utility.

The bottom panel of Figure 4 also shows the average of certainty equivalents (for illustrative purposes) and the certainty equivalent. The Weitzman model dominates. The Weitzman model is more likely than not incorrect, but higher welfare losses more than compensate for the low probability. 
Finally, the bottom panel of Figure 4 shows the ambiguity equivalent impact, assuming an ambiguity aversion of one. The ambiguity premium is small. This is because the certainty equivalent across the models already puts substantial weight on the Weitzman model - see the difference between the average certainty equivalent and the certainty equivalent in the bottom panel of Figure 4. Ambiguity aversion shift the welfare impact only a little bit further into Weitzman's direction. Table 3 shows that this holds for other parameter choices too.

\section{Discussion and conclusion}

This paper uses bootstrap and smoothed bootstrap methods to estimate the uncertainty about the total economic impact of climate change. Because there are only few primary estimates, there are substantial differences between the bootstrap and the smoothed bootstrap, with the latter being more reliable. I extend bivariate kernel density estimation, and the associated kernel regression, with a restriction - in this case, that the impact of no change is zero. The following results emerge. None of the impact functions typically assumed in climate policy analysis describes the data particularly well. Monotonic functions, typically used in more theoretical work, do particularly badly. Parabolic functions show positive but insignificant impact for moderate climate change and negative and significant impacts for large warming. Impact functions that allow for catastrophic impacts show a similar pattern for moderate climate change but diffuse effects for large warming. The uncertainty about the impact of climate change is substantial. The risk premium is therefore large. The ambiguity premium is small, however, because the risk premium absorbs most of the bad tail risk. The certainty equivalent impact is a modest $-1.5 \%$ GDP for $2.5^{\circ} \mathrm{C}$ warming, but escalates to $-15 \%$ for $5.0^{\circ} \mathrm{C}$ warming and a rate of risk aversion of one, and to $-50 \%$ for a risk aversion of two.

As with any analysis, there are caveats. Additional impact functions should be assessed, alternative specifications of the kernel distributions should be tested, and different welfare functions should be considered. I fitted function in dollar space; utility space may yield different results - although the difference is probably not that large around the global mean income. I did not consider differential impact on different regions, countries or people, which would complicate the analysis and have a considerable effect on the welfare calculus (Anthoff and Tol 2009). I do not explore the policy implications: I do not derive the marginal cost of greenhouse gas emissions, let alone place the impact functions in a welfare optimization. Most importantly, however, we need more estimates of the total impact of climate change and a way to assess the relative credibility of these estimates.

There are two striking results. First, the impact of climate change does not significantly deviate from zero for warming up to $2.5-3.5^{\circ} \mathrm{C}$ (unless monotonicity is imposed). On the one hand, this is a sobering verdict on the state of the knowledge. On the other hand, the official position that $2.0^{\circ} \mathrm{C}$ is dangerous is not well supported. The second striking result is that none of the frequently used impact functions fit very well to the pattern of the primary estimates. This is doubly sobering. Not only is the empirical evidence thin, the models used are not consistent with the evidence. See (Pindyck 2013). Decisions should be made, however, on the 
best available knowledge - even if it is not very good. The results show that, while modest warming is not a matter of great concern, more pronounced warming is.

\section{Acknowledgements}

A previous version of this paper was presented at workshops in Munich (9 July 2013) and Maynooth (6 September). The audience had excellent comments, particularly Donal O’Neill.

\section{References}

Annan, J.D. and J.C.Hargreaves (2011), 'On the generation and interpretation of probabilistic estimates of climate sensitivity', Climatic Change, 104, (3-4), pp. 423-436.

Anthoff, D. and R.S.J.Tol (2009), 'The Impact of Climate Change on the Balanced Growth Equivalent: An Application of FUND', Environmental and Resource Economics, 43, (3), pp. 351-367.

Bosello, F., F.Eboli, and R.Pierfederici (2012), 'Assessing the Economic Impacts of Climate Change', Review of Environment Energy and Economics, pp. 1-9.

Efron, B. and R.Tibshirani (1994), An introduction to the bootstrap Chapman \& Hall, London.

Fankhauser, S. (1994), 'The Economic Costs of Global Warming Damage: A Survey', Global Environmental Change, 4, (4), 301-309.

Fankhauser, S. (1995), Valuing Climate Change - The Economics of the Greenhouse, 1 edn, EarthScan, London.

Hope, C.W. (2006), 'The Marginal Impact of CO2 from PAGE2002: An Integrated Assessment Model Incorporating the IPCC's Five Reasons for Concern', Integrated Assessment Journal, 6, (1), 19-56.

Hope, C.W. (2008), 'Discount rates, equity weights and the social cost of carbon', Energy Economics, 30, (3), 1011-1019.

Karp, L. (2003), Global Warming and Hyperbolic Discounting ,Department of Economics, University of California, Berkeley.

Lange, A. and N.Treich (7-1-2008), 'Uncertainty, learning and ambiguity in economic models on climate policy: some classical results and new directions', Climatic Change, 89, (1), 7-21.

Maddison, D. and K.Rehdanz (2011), 'The impact of climate on life satisfaction', Ecological Economics, 70, (12), pp. 2437-2445.

Maddison, D.J. (2003), 'The amenity value of the climate: the household production function approach', Resource and Energy Economics, 25, (2), 155-175. 
Mendelsohn, R.O., W.N.Morrison, M.E.Schlesinger, and N.G.Andronova (2000a), 'Countryspecific market impacts of climate change', Climatic Change, 45, (3-4), 553-569.

Mendelsohn, R.O., M.E.Schlesinger, and L.J.Williams (2000b), 'Comparing Impacts across Climate Models', Integrated Assessment, 1, (1), 37-48.

Millner, A., S.Dietz, and G.M.Heal (2013), 'Scientific ambiguity and climate policy', Environmental and Resource Economics, 55, pp. 21-46.

Nordhaus, W.D. (1992), 'An Optimal Transition Path for Controlling Greenhouse Gases', Science, 258, 1315-1319.

Nordhaus, W.D. (1994a), 'Expert Opinion on Climate Change', American Scientist, 82, (1), 45-51.

Nordhaus, W.D. (1994b), Managing the Global Commons: The Economics of Climate Change The MIT Press, Cambridge.

Nordhaus, W.D. (2006), 'Geography and Macroeconomics: New Data and New Findings', Proceedings of the National Academy of Science, 103, (10), 3510-3517.

Nordhaus, W.D. (2008), A Question of Balance -- Weighing the Options on Global Warming Policies Yale University Press, New Haven.

Nordhaus, W.D. and J.G.Boyer (2000), Warming the World: Economic Models of Global Warming The MIT Press, Cambridge, Massachusetts - London, England.

Nordhaus, W.D. and Z.Yang (1996), 'RICE: A Regional Dynamic General Equilibrium Model of Optimal Climate-Change Policy', American Economic Review, 86, (4), 741-765.

Pindyck, R.S. (2013), Climate change policy: What do the models tell us?, Working Paper 19244 ,National Bureau for Economic Research, Washington DC.

Plamberk, E.L. and C.W.Hope (1996), 'PAGE95 - An Updated Valuation of the Impacts of Global Warming', Energy Policy, 24, (9), 783-793.

Rehdanz, K. and D.J.Maddison (2005), 'Climate and happiness', Ecological Economics, 52, (1), 111-125.

Roson, R. and D.van der Mensbrugghe (2012), 'Climate change and economic growth: Impacts and interactions', International Journal of Sustainable Economy, 4, (3), 270-285.

Silverman, B.W. (1986), Density Estimation Chapman and Hall, London.

Takezawa, K. (2006), Introduction to Nonparametric Regression Wiley, Hoboken.

Tibshirani, R. (1988), 'Variance stabilization and the bootstrap', Biometrika, 25, (3), 433-444.

Tol, R.S.J. (1995), 'The Damage Costs of Climate Change Toward More Comprehensive Calculations', Environmental and Resource Economics, 5, (4), 353-374. 
Tol, R.S.J. (2002a), 'Estimates of the Damage Costs of Climate Change - Part 1: Benchmark Estimates', Environmental and Resource Economics, 21, (1), 47-73.

Tol, R.S.J. (2002b), 'Estimates of the Damage Costs of Climate Change - Part II: Dynamic Estimates', Environmental and Resource Economics, 21, (2), 135-160.

Tol, R.S.J. (2009), 'The Economic Effects of Climate Change', Journal of Economic Perspectives, 23, (2), 29-51.

Tol, R.S.J. (2012a), 'On the Uncertainty about the Total Economic Impact of Climate Change', Environmental and Resource Economics.

Tol, R.S.J. (2012b), 'The Uncertainty about the Total Economic Impact of Climate Change', Environmental and Resource Economics.

van der Ploeg, F. and C.Withagen (2012), 'Too much coal, too little oil', Journal of Public Economics, 96, (1-2), pp. 62-77.

Webster, M.D., C.Forest, J.M.Reilly, M.H.Babiker, D.W.Kicklighter, M.Mayer, R.Prinn, M.Sarofim, A.P.Sokolov, P.Stone, and C.Wang (2003), 'Uncertainty analysis of climate change and policy response', Climatic Change, 61, 295-320.

Weitzman, M.L. (2012), 'GHG Targets as Insurance Against Catastrophic Climate Damages', Journal of Public Economic Theory, 14, (2), pp. 221-244.

Weitzman, M.L. (2009), 'On Modelling and Interpreting the Economics of Catastrophic Climate Change', Review of Economics and Statistics, 91, (1), 1-19.

Yohe, G.W. and R.S.J.Tol (2002), 'Indicators for Social and Economic Coping Capacity -Moving Towards a Working Definition of Adaptive Capacity', Global Environmental Change, 12, (1), 25-40. 
Table 1. Estimates of the welfare loss due to climate change (as equivalent income loss in percent); estimates of the uncertainty are given in bracket as standard deviations or $95 \%$ confidence intervals.

\begin{tabular}{|c|c|c|}
\hline Study & $\begin{array}{c}\text { Warming } \\
\left({ }^{\circ} \mathrm{C}\right)\end{array}$ & $\frac{\text { Impact }}{\text { (\%GDP) }}$ \\
\hline (Nordhaus 1994b) & 3.0 & -1.3 \\
\hline (Nordhaus 1994a) & 3.0 & $\begin{array}{r}-4.8 \\
(-30.0 \text { to } 0.0)\end{array}$ \\
\hline (Fankhauser 1995) & 2.5 & -1.4 \\
\hline (Tol 1995) & 2.5 & -1.9 \\
\hline (Nordhaus and Yang 1996) $^{\mathrm{a}}$ & 2.5 & -1.7 \\
\hline (Plamberk and Hope 1996) $^{\mathrm{a}}$ & 2.5 & $\begin{array}{r}-2.5 \\
(-0.5 \text { to }-11.4) \\
\end{array}$ \\
\hline (Mendelsohn et al. 2000a) $^{\mathrm{a}, \mathrm{b}, \mathrm{c}}$ & 2.5 & $\begin{array}{l}0.0^{\mathrm{b}} \\
0.1^{\mathrm{b}}\end{array}$ \\
\hline (Nordhaus and Boyer 2000) & 2.5 & -1.5 \\
\hline (Tol 2002a) & 1.0 & $\begin{array}{r}2.3 \\
(1.0) \\
\end{array}$ \\
\hline (Maddison 2003) $^{\mathrm{a}, \mathrm{d}}$ & 2.5 & -0.1 \\
\hline$\left(\right.$ Rehdanz and Maddison 2005) ${ }^{\mathrm{a}, \mathrm{c}}$ & 1.0 & -0.4 \\
\hline$(\text { Hope 2006) })^{\mathrm{a}, \mathrm{e}}$ & 2.5 & $\begin{array}{r}-0.9 \\
(-0.2 \text { to } 2.7) \\
\end{array}$ \\
\hline (Nordhaus 2006) & 3.0 & $\begin{array}{c}-0.9 \\
(0.1) \\
-1.1 \\
(0.1) \\
\end{array}$ \\
\hline (Nordhaus 2008) & 3.0 & -2.5 \\
\hline$\left(^{(M a d d i s o n ~ a n d ~ R e h d a n z ~ 2011) ~}{ }^{\mathrm{a}}\right.$ & 3.2 & -11.5 \\
\hline (Bosello et al. 2012) & 1.9 & -0.5 \\
\hline (Roson and van der Mensbrugghe 2012) & $\begin{array}{l}2.3 \\
4.9\end{array}$ & $\begin{array}{l}-1.8 \\
-4.6\end{array}$ \\
\hline
\end{tabular}

${ }^{\mathrm{a}}$ Note that the global results were aggregated by the current author.

b The top estimate is for the "experimental" model, the bottom estimate for the "crosssectional" model.

${ }^{\mathrm{c}}$ Mendelsohn et al. only include market impacts.

${ }^{\mathrm{d}}$ Maddison only considers non-market impacts on households.

e The numbers used by Hope are averages of previous estimates by (Fankhauser 1995) and (Tol 2002a); Stern et al. (2006) adopt the work of Hope. 
Table 2. Model likelihood.

\begin{tabular}{|l|r|r|r|r|r|}
\hline & Data & \multicolumn{2}{|c|}{ Bootstrap } & \multicolumn{2}{c|}{ Smoothed bootstrap } \\
\hline Tol & .21 & .22 & $(.03-.50)$ & .26 & $(.13-.51)$ \\
\hline Weitzman & .28 & .44 & $(.20-.97)$ & .31 & $(.18-.71)$ \\
\hline Van der Ploeg & .15 & .10 & $(.00-.20)$ & .14 & $(.01-.21)$ \\
\hline Nordhaus & .21 & .14 & $(.00-.25)$ & .16 & $(.02-.23)$ \\
\hline Hope & .15 & .09 & $(.09-.19)$ & .14 & $(.01-.19)$ \\
\hline
\end{tabular}


Table 3. The certainty equivalent total impact of climate change (in percent of income) for three alternative rates of risk aversion, two alternative warming scenarios, and five alternative models; the ambiguity equivalent is also shown, assuming a rate of ambiguity aversion of two.

\begin{tabular}{|c|c|c|c|c|c|c|c|c|}
\hline $\begin{array}{l}\text { Risk } \\
\text { aversio } \\
\mathrm{n}\end{array}$ & $\begin{array}{l}\text { Warmin } \\
\text { g } \\
\text { (Kelvin) }\end{array}$ & $\begin{array}{l}\text { Ambiguit } \\
\mathrm{y} \\
\text { Equivalen } \\
\mathrm{t}\end{array}$ & $\begin{array}{l}\text { Certainty } \\
\text { Equivalen } \\
\text { t }\end{array}$ & Tol & $\begin{array}{l}\text { Weitzma } \\
\mathrm{n}\end{array}$ & $\begin{array}{l}\text { Ploe } \\
\mathrm{g}\end{array}$ & $\begin{array}{l}\text { Nordhau } \\
\mathrm{s}\end{array}$ & $\begin{array}{l}\text { Hop } \\
\text { e }\end{array}$ \\
\hline \multicolumn{9}{|c|}{ Smoothed bootstrap } \\
\hline \multirow[t]{2}{*}{0} & 2.5 & & -1.53 & -1.57 & -1.66 & -1.65 & -1.66 & -0.87 \\
\hline & 5.0 & & -8.60 & -8.34 & -13.35 & -6.89 & -6.65 & -2.15 \\
\hline \multirow[t]{2}{*}{1} & 2.5 & -1.57 & -1.57 & -1.57 & -1.66 & -1.65 & -1.66 & -0.88 \\
\hline & 5.0 & -14.78 & -14.67 & -8.52 & -23.93 & -6.92 & -6.67 & -2.16 \\
\hline \multirow[t]{2}{*}{2} & 2.5 & -1.57 & -1.57 & -1.57 & -1.66 & -1.65 & -1.66 & -0.88 \\
\hline & 5.0 & -52.77 & -52.77 & -8.72 & -71.13 & -6.96 & -6.70 & -2.16 \\
\hline \multicolumn{9}{|c|}{ Bootstrap } \\
\hline \multirow[t]{2}{*}{0} & 2.5 & & -1.62 & -1.54 & -1.53 & -1.71 & -1.73 & -1.97 \\
\hline & 5.0 & & -17.45 & - & -29.38 & -7.14 & -6.91 & -4.86 \\
\hline \multirow[t]{2}{*}{1} & 2.5 & -1.62 & -1.62 & -1.54 & -1.54 & -1.71 & -1.73 & -1.97 \\
\hline & 5.0 & -43.34 & -41.47 & - & -67.15 & -7.16 & -6.94 & -4.87 \\
\hline \multirow[t]{2}{*}{2} & 2.5 & -1.62 & -1.63 & -1.54 & -1.54 & -1.71 & -1.73 & -1.98 \\
\hline & 5.0 & -90.34 & -90.34 & - & -95.51 & -7.18 & -6.96 & -4.88 \\
\hline
\end{tabular}




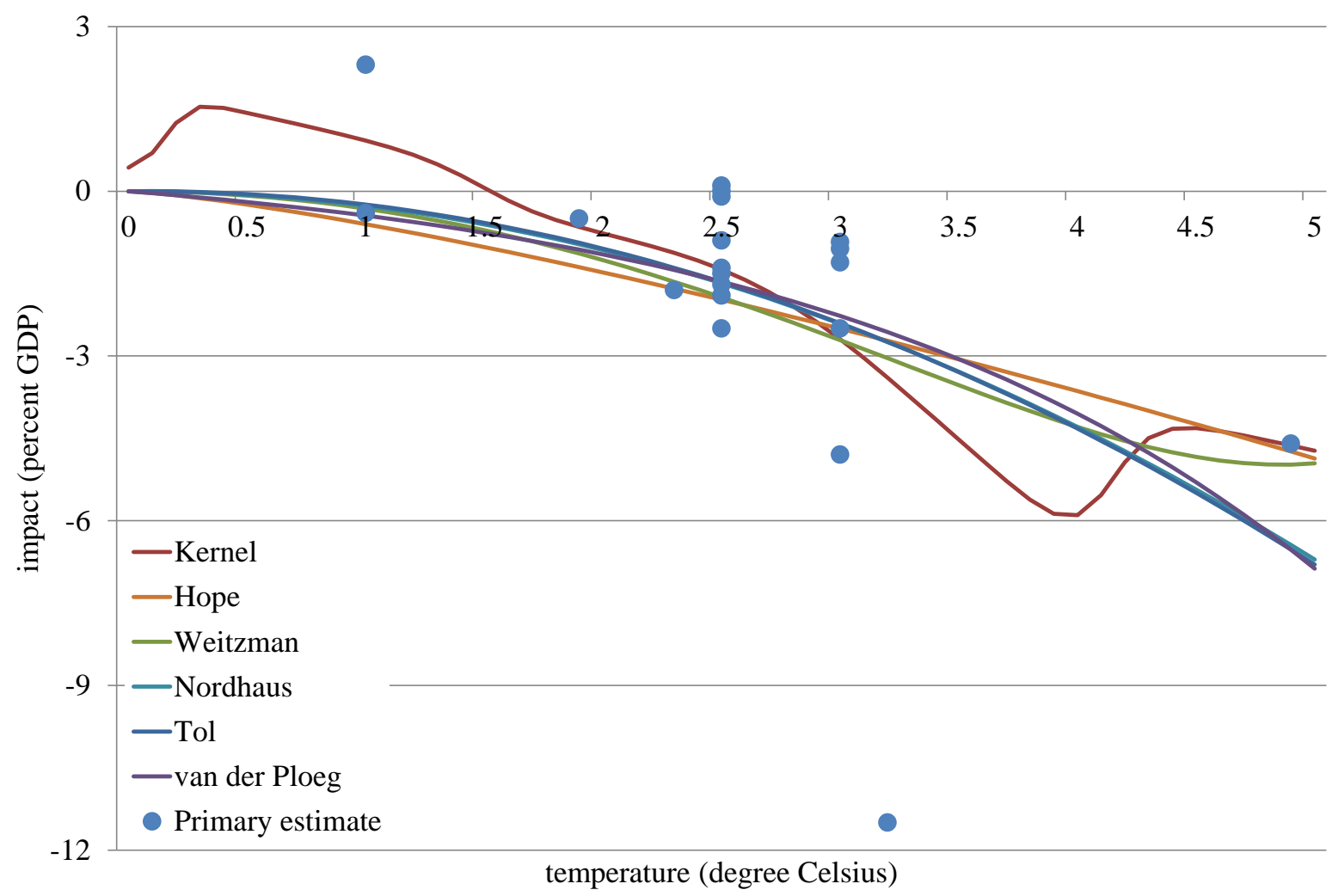

Figure 1. Primary estimates of total economic impact of climate change and six alternative fitted models (ordered by their impact at $5.0^{\circ} \mathrm{C}$ ) warming. 

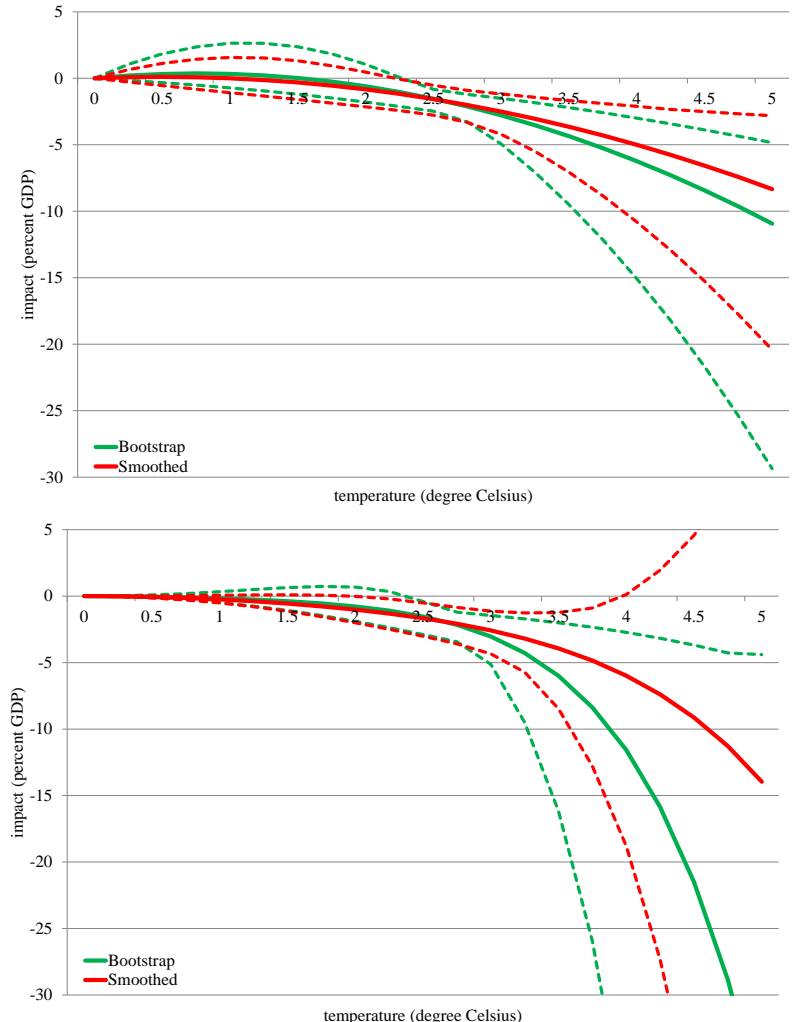

van der Ploeg

Nordhaus
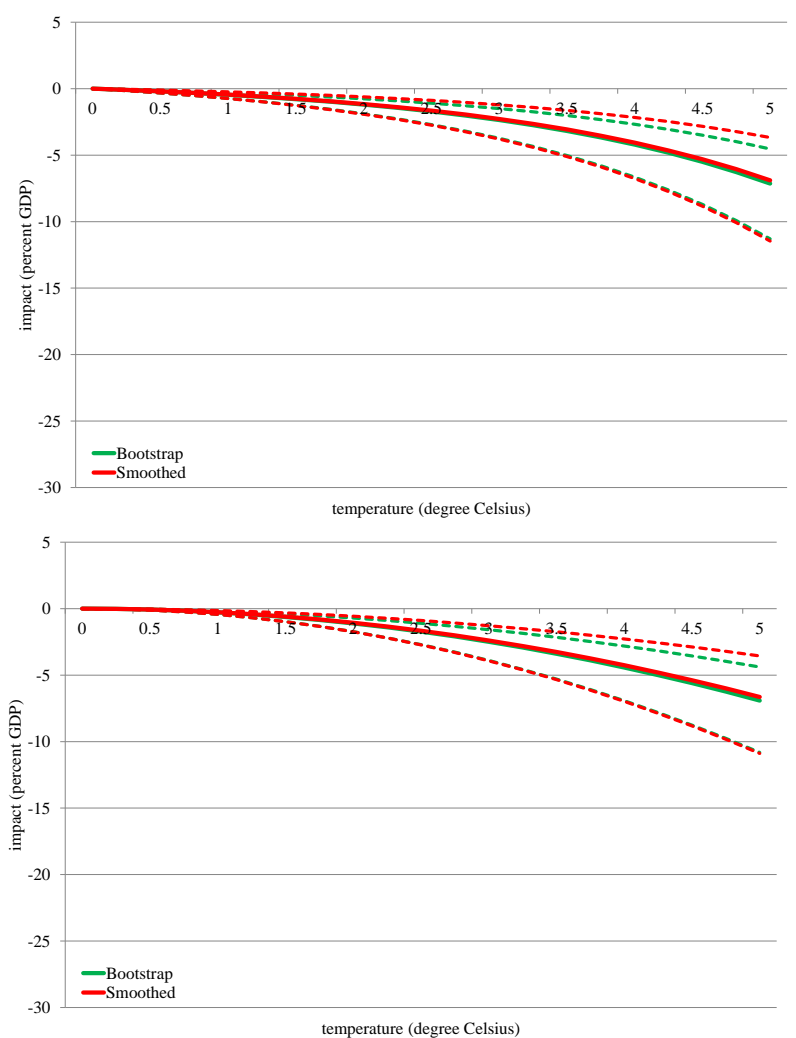

Hope

kernel 


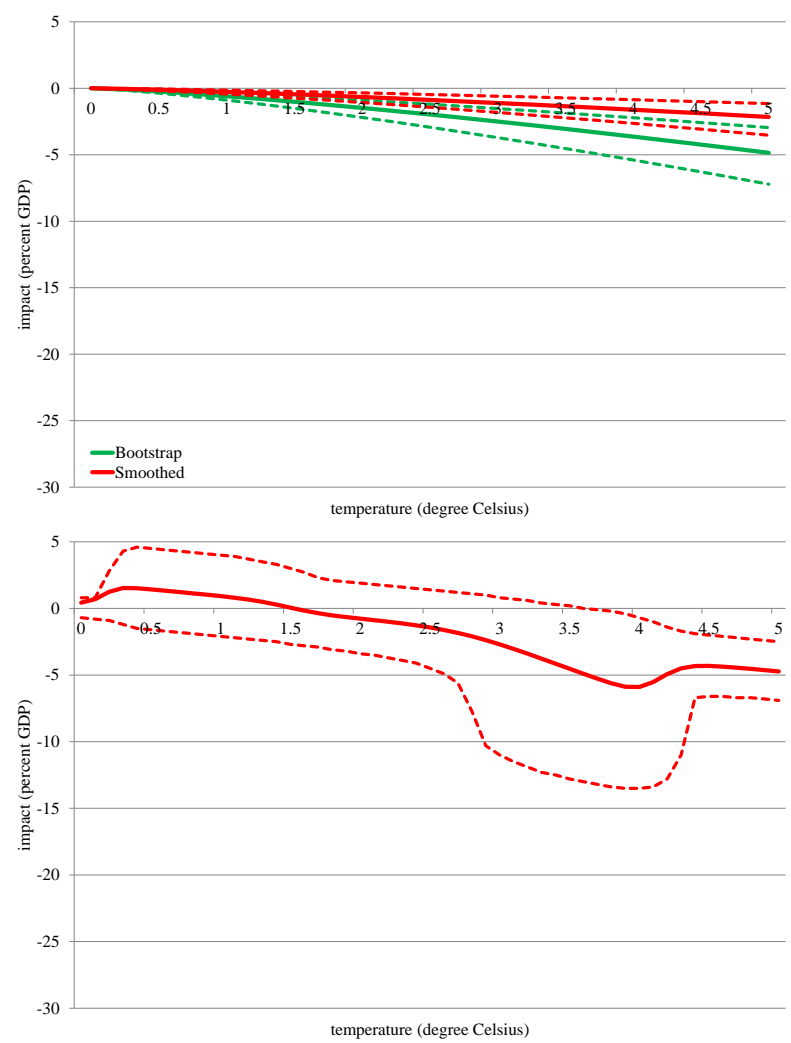

Figure 2. The expected impact of climate change and its $90 \%$ confidence interval according to six alternative models and two alternative estimation methods. 


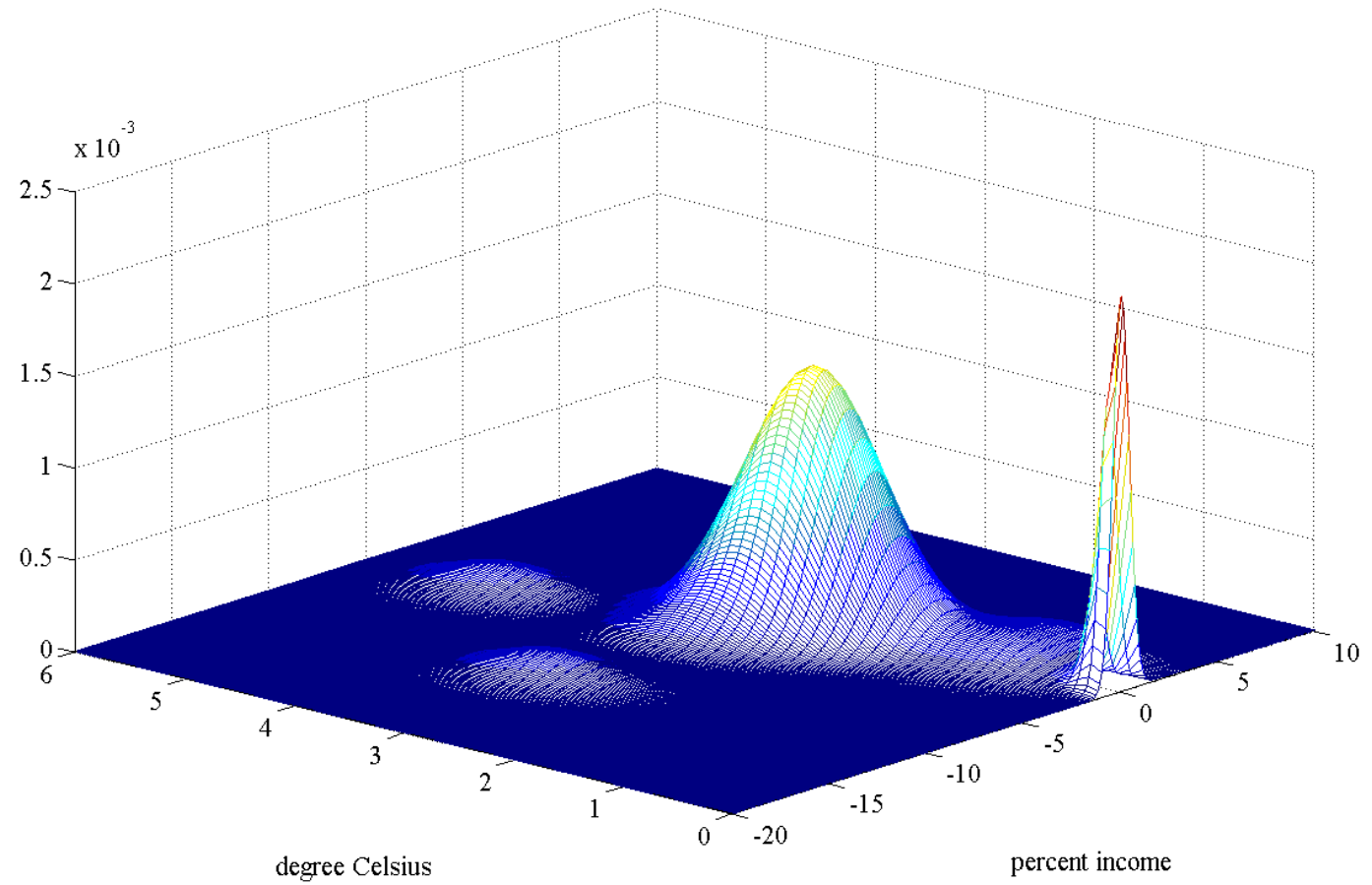

Figure 3. Bivariate kernel density of temperature and impact. 


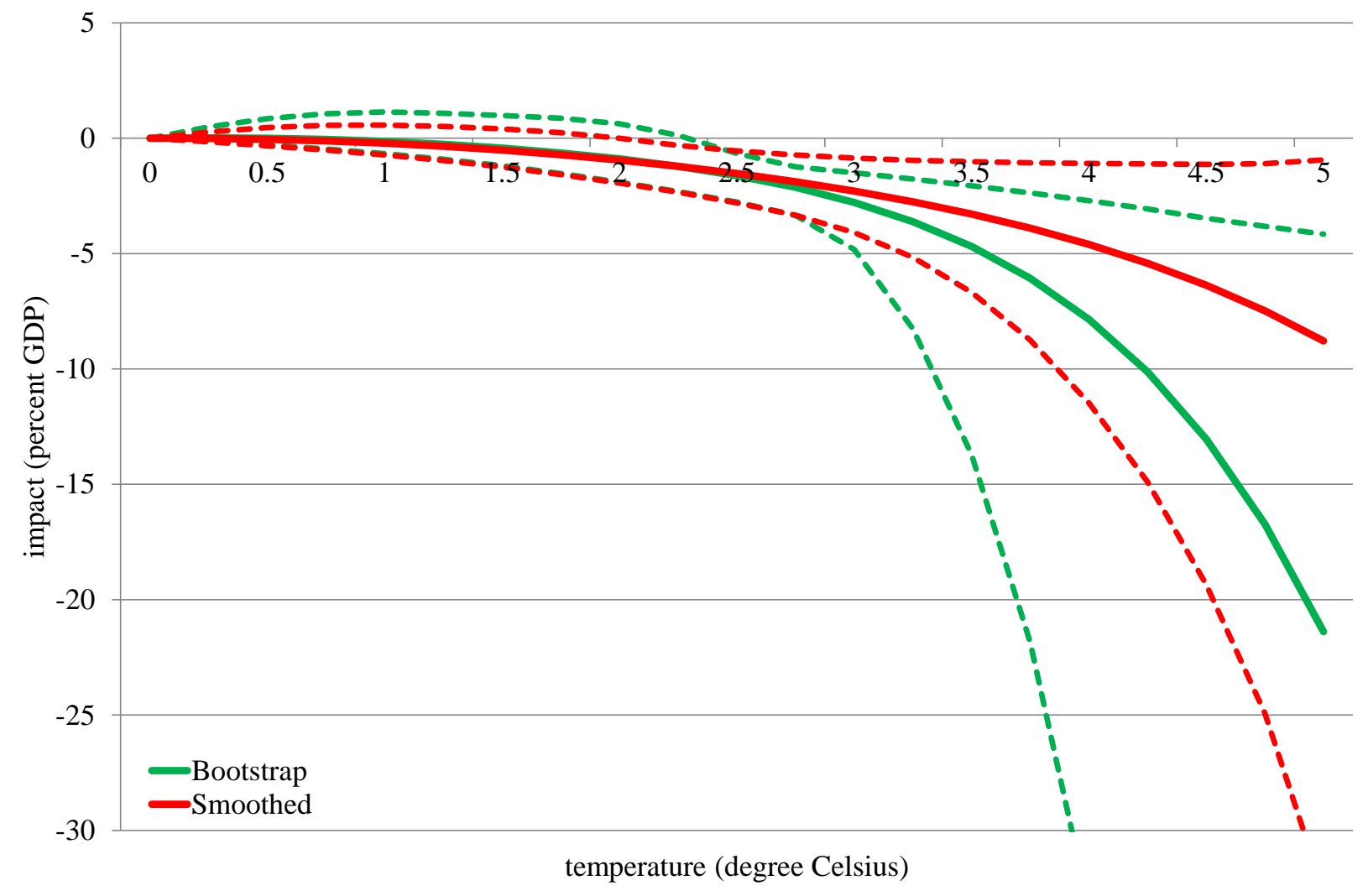

Figure 4 . The expected impact of climate change and its 90\% confidence interval according to the Bayesian average of six alternative models and two alternative estimation methods 

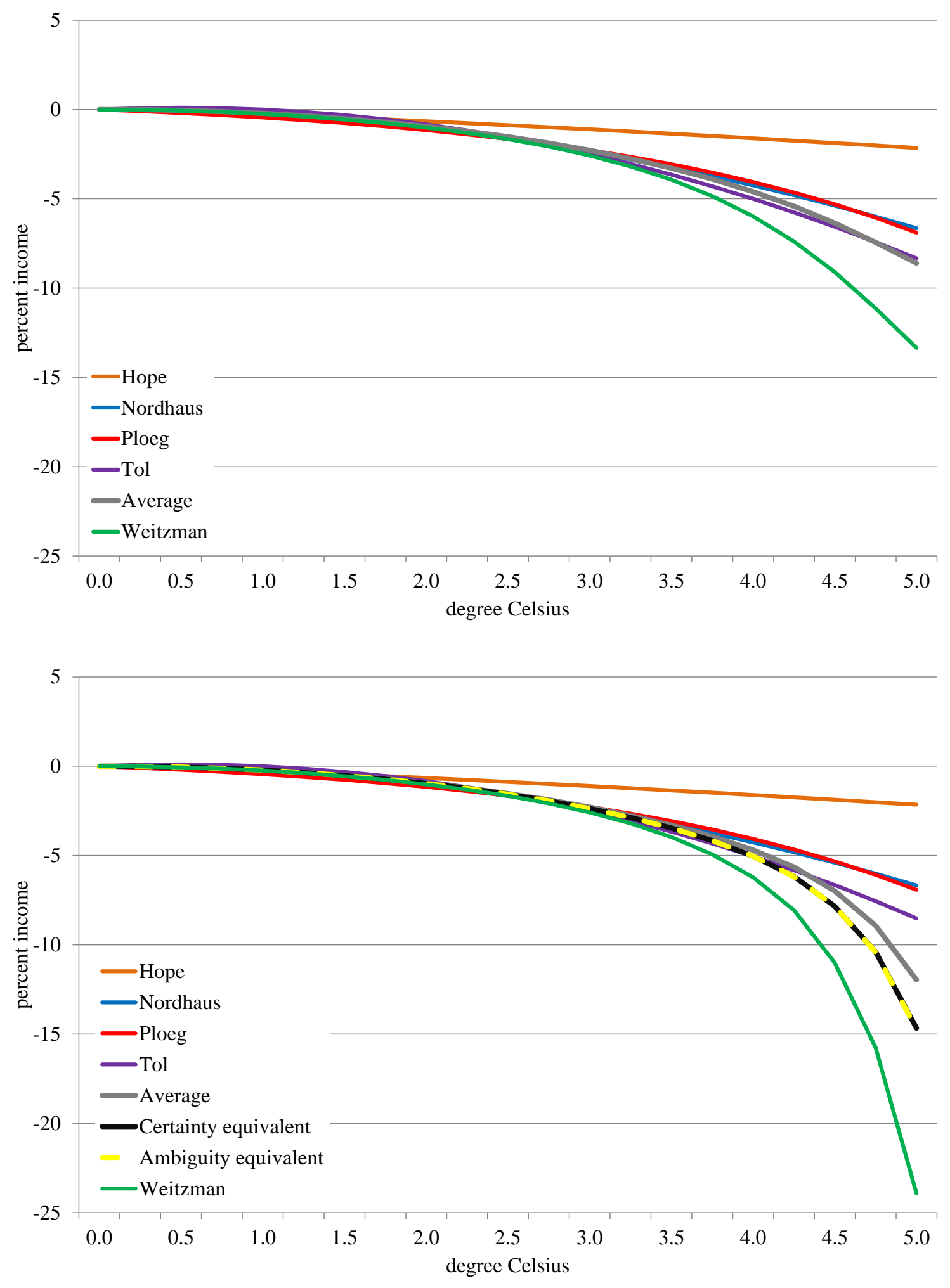

Figure 5. Expected impacts for individual models and the weighted model average (top panel); certainty equivalent impacts for individual models, the weighted average of the certainty equivalents, the certainty equivalent impact and the ambiguity equivalent impact (bottom panel). 


\section{APPENDIX: BANDWIDTH SELECTION FOR KERNEL REGRESSION WITH RESTRICTIONS}

Section 4 introduces restricted kernel regression by adding an artificial data point representing the restriction. (This is readily generalized to multiple restrictions.) The bandwidth of the restriction should be selected such that the kernel regression is not materially affected where there are observations while maintaining smoothness. Figure A1 shows that, if the same bandwidth is chosen for the restriction as for the actual observations, the kernel function is lower for the first observations. If the bandwidth is 100 times smaller, the kernel function sharply bends near zero. A bandwidth of one-tenth is an acceptable, yet ad hoc compromise.

The Matlab code can be found at http://ideas.repec.org/c/sus/susesa/0313.html

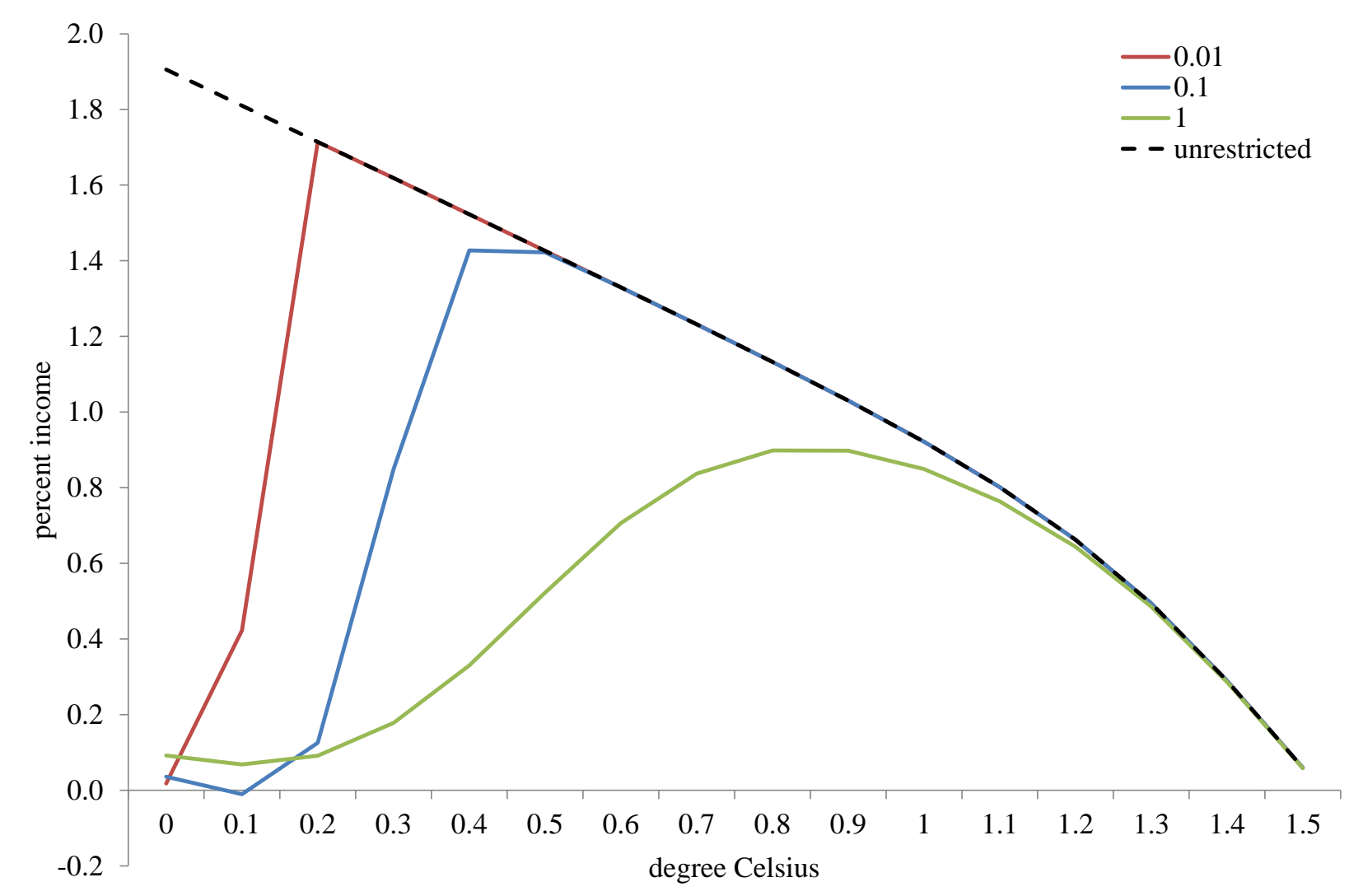

Figure A1. Kernel regression of impact on temperature where the restriction $I(T=0)=0$ has the same bandwidth as the observations (' 1 '), one-tenth of that bandwidth (' 0.1 ') or onehundredth ('0.01'); the unrestricted kernel function is shown for comparison. 